\title{
It's all about seeing and hearing: the Editors' and Readers' Choice Awards 2022
}

\author{
Günther K. H. Zupanc ${ }^{1}(0) \cdot$ Kentaro Arikawa ${ }^{2}$. Charlotte Helfrich-Förster ${ }^{3} \cdot$ Uwe Homberg $^{4} \cdot$ Peter M. Narins ${ }^{5}$. \\ Wolfgang Rössler ${ }^{6} \cdot$ Andrea Megela Simmons $^{7} \cdot$ Eric J. Warrant $^{8}$
}

Received: 4 January 2022 / Revised: 6 January 2022 / Accepted: 7 January 2022 / Published online: 2 February 2022

(c) The Author(s), under exclusive licence to Springer-Verlag GmbH Germany, part of Springer Nature 2022

\begin{abstract}
This year marks the inauguration of the annual Editors' Choice Award and the Readers' Choice Award, each presented for outstanding original papers and review articles published in the Journal of Comparative Physiology A. The winners of the 2022 Editors' Choice Award were determined by vote of the Editorial Board for the most highly recommended papers published in Volume 207 in 2021. They are 'Visual discrimination and resolution in freshwater stingrays (Potamotrygon motoro)' by Daniel et al. (J Comp Physiol A 207, 43-58, 2021) in the Original Paper category; and 'Neurophysiology goes wild: from exploring sensory coding in sound proof rooms to natural environments' by Römer (J Comp Physiol A 207, 303-319, 2021) in the Review Article category. The 2022 Readers' Choice Award was based on access number of articles published in Volume 206 in 2020, to ensure at least 12-month online presence. It is given to Nicholas et al. for their original paper titled 'Visual motion sensitivity in descending neurons in the hoverfly' (J Comp Physiol A 206, 149-163, 2020); and to Schnaitmann et al. for their review article entitled 'Color vision in insects: insights from Drosophila' (J Comp Physiol A 206, 183-198, 2020).
\end{abstract}

Keywords Journal of Comparative Physiology A · Editors' Choice Award · Readers' Choice Award · Sensory physiology · Neuroethology

Handling Editor: Friedrich G. Barth.

Günther K. H. Zupanc

g.zupanc@northeastern.edu

1 Department of Biology, Northeastern University, Boston, MA 02115, USA

2 Department of Evolutionary Studies of Biosystems, SOKENDAI (The Graduate University for Advanced Studies), Hayama 240-0115, Kanagawa, Japan

3 Neurobiology and Genetics, Biocentre, University of Würzburg, 97074 Würzburg, Germany

4 Department of Biology, Philipps-University of Marburg, 35032 Marburg, Germany

5 Departments of Integrative Biology \& Physiology, and Ecology \& Evolutionary Biology, University of California at Los Angeles, Los Angeles, CA 90095, USA

6 Behavioral Physiology and Sociobiology (Zoology II), Biocentre, University of Würzburg, 97074 Würzburg, Germany

7 Department of Cognitive, Linguistic and Psychological Sciences, Brown University, Providence, RI 02912, USA

8 Department of Biology, University of Lund, 22362 Lund, Sweden

\section{Excellence in publication}

What is known today as the Journal of Comparative Physiology A was founded in 1924 by Karl von Frisch under its German title, Zeitschrift für Vergleichende Physiologie. It was the first scientific journal specifically dedicated to the publication of studies in the then emerging field of comparative physiology. Since then, many of the investigations that appeared in the Journal have driven the evolution of the comparative branches of sensory physiology and neurophysiology, and subsequently, of neuroethology (for a brief historical account see Zupanc 2021). The impact that the Journal of Comparative Physiology A continues to have until today is evident from the many excellent articles published every year. To recognize these accomplishments, the Editorial Board decided to bestow two annual awards, inaugurated in 2022: the Editors' Choice Award and the Readers' Choice Award, each presented in the categories Original Paper and Review Article (the latter including Review-History and Perspectives). 


\section{The Editors' Choice Awards 2022}

For the Editors' Choice Award 2022, any article published in Volume 207 (2021) was eligible, except papers (co-) authored by a member of the Editorial Board. The selection of the winners was based on independent votes cast by each member. First and second choices were indicated by 2 points or 1 point, respectively.

The first round of voting instantly produced a clear winner in the category Review Article. Heiner Römer's ReviewHistory article titled 'Neurophysiology goes wild: from exploring sensory coding in sound proof rooms to natural environments' (Römer 2021) received a remarkable score, 14 out of 16 points.

In his review, Römer describes how neurophysiology has gone "wild", and why going wild is an important advance in our understanding of brain control of behavior. A central goal of sensory neuroethology is to unravel how sensory systems encode the outside world. Historically, a guiding framework in this search has been Barlow's concept of efficient coding, which postulates that behaviorally-relevant features of the sensory world are filtered neurally in such a way as to reduce redundancy without losing critical information (Barlow 1961). Relevant stimuli provide more information, i.e., are coded more efficiently, than "artificial" stimuli, and so the brain is "adapted" to receiving them. As Römer elegantly discusses, the issue then becomes how to define behavioral relevance and to determine how behavioral relevance can vary in different physical environments. Focusing on the acoustic communication systems of insects, he reviews how the analysis of neural coding of sensory stimuli has progressed from early laboratory-based research focusing on responses to simple or synthetic sounds, to the pioneering work of Roeder and Treat (1957) describing how moth tympanic organs detect the actual ultrasonic sounds of their bat predators, and finally to the introduction of portable systems allowing single neuron recordings to complex, natural stimuli directly in the natural environment. Römer's integration of historical experiments, modern technical advances, and new conceptual developments, such as theories of sensory drive and receiver biases (Endler 1992), set a new framework for moving sensory neuroethology forward.

In the Original Paper category, the votes cast in the first round revealed a more complex picture. Three articles (Brandt et al. 2021; Daniel et al. 2021; Lin and Hedwig 2021) received 4 (out of 16) points each, reflecting the difficulty of the Editorial Board to select a top candidate from many excellent contributions. In the second round of voting, the majority of the Editorial Board members voted for the article on 'Visual discrimination and resolution in freshwater stingrays (Potamotrygon motoro)' by Daniel et al. (2021).

The study reported in this paper is in the best tradition of the Journal of Comparative Physiology A. In the first issue of the Journal, Friedrich Schiemenz presented a novel conditioning paradigm to examine color vision in sticklebacks and minnows (Schiemenz 1924). Daniel et al. (2021) used a similar behavioral approach, in which one visual stimulus was associated with food reward while the other was not, to explore, in the laboratory, various aspects of visual discrimination abilities of the ocellate river stingray (Potamotrygon motoro). The Editorial Board was impressed by the exemplary detailed behavioral analysis carried out by the authors, which provides an excellent foundation for future field studies and laboratory experiments combining behavioral analysis with anatomical work.

\section{The Readers' Choice Awards 2022}

The winners of the Readers' Choice Award in the categories Original Paper and Review Article were determined by the number of online accesses (as a proxy of 'popularity') of pieces that appeared in Volume 206 (2020). The year 2020, instead of 2021, was chosen to ensure that each article published had been available online for at least 12 months before a decision was made on December 8, 2021.

The winner in the Original Paper category was 'Visual motion sensitivity in descending neurons in the hoverfly' by Nicholas et al. (2020) with 2036 accesses, followed by the articles of Dombrovski et al. (2020) and Milne et al. (2020) with 1832 and 1738 accesses, respectively.

In their study, Nicholas and colleagues investigated the properties of a specialized group of visual motion-sensitive cells in the brain of the male drone fly Eristalis tenax. These neurons - called target-selective descending neurons (or TSDNs) - carry visual signals from the brain, through the neck of the fly, to motor neurons in the thoracic ganglia where the information is used to steer airborne mate pursuit. Some TSDNs were found to be highly sensitive to the motions of small dark targets (like a flying female fly against the sky), while others preferentially responded to a looming target (as a female would appear as the male closes in). TSDNs were first discovered in dragonflies by Robert M. Olberg around 40 years ago (Olberg 1981, 1986), and these pioneering findings were also published in the Journal of Comparative Physiology A. The enduring interest in how sensory information is used to steer insect locomotion is certainly a major factor in the popularity of this paper with our readers.

The front-runner in the Review Article category was 'Color vision in insects: insights from Drosophila' by Schnaitmann et al. (2020). It was accessed 6,436 times. Its closest competitors were the articles by Zhao and McBride (2020) and Borst et al. (2020) with 5,218 and 4,698 accesses, respectively.

In their article, Schnaitmann and colleagues review the fundamental concepts of color vision, alongside the current 
understanding of the neuronal basis of this phenomenon, in the fruit fly Drosophila melanogaster. In 1914, the pioneering work of Karl von Frisch showed, for the first time, that honeybees can distinguish colors (von Frisch 1914). Since then, numerous studies on color vision in various insects have been published in the Journal of Comparative Physiology A. After introducing the key roles of insect color vision from a comparative view, Schnaitmann et al. elegantly explain the concept of photoreceptor opponency as a hallmark of color vision. They describe the photoreceptor arrangement and photopigment composition in the ommatidia of fruit flies, honeybees, and Papilio butterflies; and they discuss the ability to discriminate different wavelengths in these three insect taxa, before going into details of the circuit mechanisms underlying color vision in the fruit fly. Throughout their journey, they always maintain a comparative perspective on other insects. The review is illustrated with four excellent figures that make even the complex circuitry in the fly eye comprehensible.

Congratulations to the recipients of the 2022 Editors' and Readers' Choice Awards! We look forward to receiving many more outstanding contributions like these from our authors.

\section{Declarations}

Conflict of interest The authors declare no conflicts of interest.

\section{References}

Barlow HB (1961) Possible principles underlying the transformations of sensory messages. In: Rosenblith WA (ed) Sensory communication. MIT Press, Cambridge, MA, pp 217-234

Borst A, Haag J, Mauss AS (2020) How fly neurons compute the direction of visual motion. J Comp Physiol A 206:109-124. https://doi. org/10.1007/s00359-019-01375-9

Brandt EE, Sasiharan Y, Elias DO, Mhatre N (2021) Jump takeoff in a small jumping spider. J Comp Physiol A 207:153-164. https:// doi.org/10.1007/s00359-021-01473-7

Daniel MMM, Alvermann L, Böök I, Schluessel V (2021) Visual discrimination and resolution in freshwater stingrays (Potamotrygon motoro). J Comp Physiol A 207:43-58. https://doi.org/10.1007/ s00359-020-01454-2

Dombrovski M, Kuhar R, Mitchell A, Shelton H, Condron B (2020) Cooperative foraging during larval stage affects fitness in Drosophila. J Comp Physiol A 206:743-755. https://doi.org/10.1007/ s00359-020-01434-6

Endler JA (1992) Signals, signal conditions, and the direction of evolution. Am Nat 139:S125-S153

Lin C-C, Hedwig B (2021) Lesions of abdominal connectives reveal a conserved organization of the calling song central pattern generator (CPG) network in different cricket species. J Comp Physiol A 207:533-552. https://doi.org/10.1007/s00359-021-01495-1

Milne AO, Smith C, Orton LD, Sullivan MS, Grant RA (2020) Pinnipeds orient and control their whiskers: a study on Pacific walrus, California sea lion and Harbor seal. J Comp Physiol A 206:441451. https://doi.org/10.1007/s00359-020-01408-8

Nicholas S, Leibbrandt R, Nordström K (2020) Visual motion sensitivity in descending neurons in the hoverfly. J Comp Physiol A 206:149-163. https://doi.org/10.1007/s00359-020-01402-0

Olberg RM (1981) Object- and self-movement detectors in the ventral nerve cord of the dragonfly. J Comp Physiol A 141:327-334. https://doi.org/10.1007/BF00609935

Olberg RM (1986) Identified target-selective visual interneurons descending from the dragonfly brain. J Comp Physiol A 159:827840. https://doi.org/10.1007/BF00603736

Roeder KD, Treat AE (1957) Ultrasonic reception by the tympanic organ of noctuid moths. J Exp Zool 134:127-157. https://www. ncbi.nlm.nih.gov/pubmed/13428949

Römer H (2021) Neurophysiology goes wild: from exploring sensory coding in sound proof rooms to natural environments. J Comp Physiol A 207:303-319. https://doi.org/10.1007/ s00359-021-01482-6

Schiemenz F (1924) Über den Farbensinn der Fische. Z Vergl Physiol 1:175-220. https://doi.org/10.1007/BF00338212

Schnaitmann C, Pagni M, Reiff DF (2020) Color vision in insects: insights from Drosophila. J Comp Physiol A 206:183-198. https:// doi.org/10.1007/s00359-019-01397-3

von Frisch K (1914) Der Farbensinn und Formensinn der Biene. Zool Jahrb. Abt allg Zool Physiol Tiere 35:1-188. https://www.biodi versitylibrary.org/item/44193

Zhao Z, McBride CS (2020) Evolution of olfactory circuits in insects. J Comp Physiol A 206:353-367. https://doi.org/10.1007/ s00359-020-01399-6

Zupanc GKH (2021) The Journal of Comparative Physiology A: rooted in great tradition, committed to innovation and discovery. J Comp Physiol A 208. https://doi.org/10.1007/s00359-021-01526-X

Publisher's Note Springer Nature remains neutral with regard to jurisdictional claims in published maps and institutional affiliations. 